Editorial

\title{
Home, Housing and Communities: Foundations for Inclusive Society
}

\author{
Isobel Anderson ${ }^{1, *}$, Joe Finnerty ${ }^{2}$ and Vikki McCall ${ }^{1}$ \\ ${ }^{1}$ Faculty of Social Sciences, University of Stirling, Stirling, FK9 4LA, UK; E-Mails: isobel.anderson@stir.ac.uk (I.A.), \\ vikki.mccall1@stir.ac.uk (V.M.) \\ ${ }^{2}$ School of Applied Social Studies, University College Cork, Cork, T12YN60, Ireland; E-Mail: j.finnerty@ucc.ie \\ * Corresponding author
}

Submitted: 27 July 2020 | Published: 31 July 2020

\begin{abstract}
This issue of Social Inclusion explores the interconnected, but multi-faceted concepts of home, housing and communities as fundamental tenets of an inclusive society. Our editorial introduces our motivation for this topic, outlines the contributions to the collection and highlights some crosscutting themes, which emerge from the articles. The research presented was largely completed in advance of the full impact of the 2020 global coronavirus pandemic. In concluding the editorial, we reflect on the equal centrality of home, housing and communities to surviving the pandemic and ensuing economic crisis and encourage greater commitment to home and housing as a human right to mitigate social and economic inequality and underpin sustainable, inclusive settlements for the future.
\end{abstract}

\section{Keywords}

communities; empowerment; home; homelessness; housing; human right to housing; neighbourhood

\section{Issue}

This editorial is part of the issue "Home, Housing and Communities: Foundations for Inclusive Society" edited by Isobel Anderson (University of Stirling, UK), Vikki McCall (University of Stirling, UK) and Joe Finnerty (University College Cork, Ireland).

(C) 2020 by the authors; licensee Cogitatio (Lisbon, Portugal). This article is licensed under a Creative Commons Attribution 4.0 International License (CC BY).

\section{Introduction: Inclusive Homes, Housing and Communities}

Our motivation for this themed issue builds on the 2016 special issue on homelessness and social inclusion (Anderson, Filipovič Hrast, \& Finnerty, 2016) and the overriding requirement for "access to good quality and affordable accommodation" (Anderson et al., 2016, p. 2) as a fundamental dimension of social inclusion. A focus on the social dimension of housing was core to the call for articles for this volume. Across the globe, nation states face enormous challenges in meeting housing needs across diverse communities, and social sustainability became a key concern for the 2030 sustainable development agenda with the significant inclusion of a specific Sustainable Development Goal (no. 11) on housing and sustainable settlements (Cociña, Frediani, Acuto, \& Levy, 2019; UN HABITAT, 2015; United Nations, 2015 ).
The contributions here present new research that casts the social role of housing as central to the exploration of the significance of home and the flourishing of communities. The articles draw on a range of theoretical perspectives, including rights based approaches, empowerment and co-production, realist theory and institutional theories. They also develop a range of innovative research methods to explore the role of housing in addressing inequality. Housing meets a fundamental need for physical shelter and contributes to psychological well-being by fulfilling a sense of personal space, autonomy, and privacy. However, housing per se does not deliver this, where the housing is unsafe, inadequate or lacks privacy-i.e., falling into the 'houseless,' 'insecure,' and 'inadequate' categories of the European Typology of Homelessness and Housing Exclusion (Edgar, 2012). Housing, necessarily located in a particular geographical space, may also create and affirm a sense of social 
and cultural community. The links between (the right to) housing and (the right to) other "goods" are many and varied, for example, security and dignity, privacy, a family life, social inclusion, cultural diversity and health, and non-discrimination (Donnelly, Finnerty, \& O'Connell, 2020). A rights-led approach to understanding housing within society emerges as a valuable overarching framework in many of the articles in this volume.

\section{Overview of Contributions}

The articles presented here provide a wide range of new evidence and approaches on the nexus of housing, home and community, from five European countries and from Australia.

Three articles present broad overviews of the challenges for housing in contributing to an inclusive society. Maloutas, Siatitsa, and Balampanidis (2020, in Greece) and Tunstall (2020, in England and Wales) both critique housing policies and outcomes over the long term in differing national contexts, while McCall et al. (2020, Scotland, England and Wales) present an innovative approach to forward planning for housing in the context of an aging society. Maloutas et al.'s (2020) review of housing policy in Athens illustrates how some countries mainly provided opportunities for affordable housing in the post-war period through low-cost homeownership. Their analysis also demonstrates a process of loss of social integration through increasingly unequal access to housing associated with a lack of policies to regulate the 'untrammelled' housing market. The urgent case is made for inclusive housing policies to combat marketgenerated inequalities. Tunstall's examination of housing growth in terms of space per person in England and Wales over 1981-2011, develops novel conceptions of 'inclusive growth' (benefitting the worst off) and 'just growth' (preventing an increase in inequality). Although housing space did increase, the growth was neither inclusive nor just as housing inequality rose and there was no evident gain for the poorest groups. Tunstall (2020) also concludes that major changes in the national housing system are needed to address these unequal outcomes. McCall et al. (2020) scrutinise the effectiveness of planning for an ageing population across the housing sector in Scotland, England and Wales. Using an innovative 'Serious Game' approach involving policy makers, practitioners and service users, tackling inequality again emerged as a key challenge requiring placing housing at the heart of service integration and supporting the coproduction of decision-making across social policy, services, and stakeholder groups.

The next set of four articles look at lived experience of home and homelessness across community groups that often face particular disadvantage in access to housing. Sahlin (2020, in Sweden) contrasts the experience of homelessness for migrants with that of national citizens. Articles by Anderson, Theakstone, and Lawrence (2020, in Scotland) and Ellis, Munoz,
Narzisi, Bradley, and Hall (2020, in Scotland) both examine disabled people's pathways to independent living and the transformational potential of suitable housing. O'Sullivan, O'Connell, and Byrne (2020, Ireland) foreground the too often neglected perspectives of children and young people in their study of housing regeneration. Drawing on Simmel's (1965) definition of poverty in relation to public assistance, Sahlin's (2020) analysis of Swedish Parliamentary discourse (2015-2019) reveals how discussion of homelessness became increasingly nationalistic, prioritising ethnic belonging and national origin above people's lived experience and housing needs. Societies acknowledge responsibility to give shelter to certain groups, while excluding large numbers experiencing housing exclusion under the ETHOS typology (Edgar, 2012). Anderson et al. (2020) examine accessible social rented housing as a route to independent living for disabled people. Underpinned by principles of disabled-led co-production, the study compared perspectives of housing providers and tenants/applicants. As with national overviews, local level practice revealed a continuing gap between the needs of disabled people and what housing providers were able to deliver. The processes of moving into a purpose-built estate of smart homes for a diverse group of disabled people were analysed in Ellis et al.'s (2020) in-depth qualitative case study. Experiences prior to moving and following relocation revealed the positive impact of moving into suitable smart homes on residents' wellbeing and feelings of inclusion. Shifting the focus to that of community, for an often excluded group, O'Sullivan et al. (2020) present the perspectives of children and young people living through the regeneration of a large social housing estate. The research reveals their lack of involvement in the decision-making process, as well as their experiences of poverty, stigma and exclusion. Creative and participatory methods adopted in this study are also required in practice to deliver more inclusive regeneration programmes that value the voices of children and young citizens in society.

The final three articles explore the wider importance of neighbourhoods and communities to promoting housing inclusion. Tually, Skinner, Faulkner, and GoodwinSmith (2020, Australia) connect home and community building to social housing, while Rolfe and Garnham (2020, Scotland) look at the neighbourhood and wellbeing effects for new tenants moving from precarious to secure housing. The closing article by Robertson et al. (2020, in Scotland) illustrates the importance of neighbourhood and community to a broader sense of belonging, beyond home as a dwelling. Tually et al. (2020) explore the transfer of public housing stock to the community housing sector in a disadvantaged area. The programme, founded in community development and placemaking to promote social inclusion, was valued by residents and other stakeholders. Co-production developed new structures for participation, building confidence in the social landlord and greater sense of a safe home and inclusive community for residents. The study presents a 
transferable model to tackle structural disadvantage associated with excluded communities. Rolfe and Garnham (2020) then explore the effects of neighbourhood on health and wellbeing of predominantly low-income new tenants of three types of housing organisation. Their longitudinal, mixed-methods study found that analysis of neighbourhood effects as causal factors was required to help housing organisations deliver a more inclusive tenant experience. For example, where social housing stock is geographically concentrated, landlords could invest in local amenities and the built environment, while those (mainly private sector) landlords with dispersed portfolios had more capacity to offer tenants greater choice of area. In a contribution that focuses on the outdoor environment, Robertson et al. (2020) demonstrate how inclusive walking groups support people with dementia to remain connected in their communities. Methodologically, this research incorporated 'walking interviews' and discussions with people living with dementia, as well as other stakeholders in a national programme of dementiafriendly walking groups.

\section{Conclusions in a Shifting Context}

A number of interconnected threads emerge across the articles in this volume. Themes of empowerment and co-production across key stakeholders have become increasingly central to social research and to policy development. Longitudinal analysis better capturing 'process' through quantitative and qualitative methods enhances understanding of change over time. Innovation in methods has also ensured the involvement of disadvantaged groups, sometimes considered 'hard to reach.' The continuing importance of housing design is supported by the sustainability agenda, technology assisted living and Smart Homes. Contributions demonstrate the importance of national and local levels of analysis, the need to ensure fair representation of those who face disadvantage in the housing system and the potential transferability of innovative research methods and research findings to further enhancing the evidence base. Issues of inequality and social justice are addressed throughout, often in relation to housing rights and human rights. Evidence indicates how housing can still be either exclusionary or inclusive, revealing systemic gaps but also important successes and transferable models for future policy and practice. Scope remains for governments and non-government actors to adopt much more proactive approaches to delivering on equalities agendas (Matthews \& Poyner, 2019; Matthews, Poyner, \& Kjellgren, 2019).

Our thematic issue emerges some months into the 2020 global coronavirus pandemic, with most countries still facing a public health and economic crisis that may turn out to be a once in a 100-year event. We know already that the pandemic impacted highly unevenly across age, race and social class (McKee, Pearce, \& Leahy, 2020). The public health crisis rapidly affected multi- ple dimensions of the economy and government including health care, education, transport, and employment. Homes, housing and communities were also settings for both lived inequality and possible pathways to protection. Media attention focused on health care responses, but frontline housing and homelessness services also reacted urgently to protect tenancies and communities, and to support roofless people into emergency accommodation (Fondation Abbé Pierre \& FEANTSA, 2020). During critical phases of staying and working at home, differentiated housing conditions exposed inequalities in terms of space for childcare/home education, home working, home shielding, self-isolation and digital connectivity. Taking the example of the UK, community organisations were vital to delivering local self-help and support to vulnerable households, but the particular vulnerability of older households was exacerbated in institutional settings constrained by the neglect of social care policy. In June 2020, the UN Special Rapporteur on the right to adequate housing issued a call for evidence on housing issues to feed into a report to the General Assembly on Covid-19 and the right to housing (United Nations Human Rights, Office of the High Commissioner, 2020). Future analysis would benefit from more fully considering housing as social determinant of health (Rolfe et al., 2020) and a key social provision to underpin future social protection and resilience. The ensuing economic and social challenges will demand further creative responses from housing agencies to delivering the benefits of homes and communities post-pandemic, albeit with necessarily different approaches to pre-pandemic.

No single grand theory links all aspects of Home, Housing and Communities but greater recognition of the importance of housing as a human right does bind many of the issues addressed in this thematic issue and in wider housing and communities research. Housing as a fundamental human right remains crucial to tackling economic inequality and social exclusion and is arguably as relevant to the 'Me Too' and 'Black Lives Matter' movements as to the coronavirus pandemic and to the 2030 sustainable development agenda that no one should be left behind. A Housing Rights approach can galvanise stakeholders at global, national and local levels, as well as empower disadvantaged groups and communities to deliver adequate affordable homes and safe sustainable communities for all.

\section{Acknowledgments}

We are extremely grateful to the authors for their contributions, to referees who contributed invaluable reviews, and to the Social Inclusion editorial team for supporting this thematic issue.

\section{Conflict of Interests}

The authors declare no conflict of interests. 


\section{References}

Anderson, I., Filipovič Hrast, M., \& Finnerty, J. (2016). Researching homelessness: Challenging exclusion? Social Inclusion, 4(4), 1-4.

Anderson, I., Theakstone, D.-D., \& Lawrence, J. (2020). Inclusive social lettings practice: Opportunities to enhance independent living for disabled people. Social Inclusion, 8(3), 54-65.

Cociña, C., Frediani, A., Acuto, M., \& Levy, C. (2019). Knowledge translation in global urban agendas: A history of research-practice encounters in the Habitat conferences. World Development, 122, 130-141.

Donnelly, D., Finnerty, J., \& O'Connell, C. (2020). The right to housing. In F. O'hAdhmaill (Ed.), Critical perspectives on international human rights and social policy: Global welfare and development (pp. 209-221). Bristol: Policy Press.

Edgar, B. (2012). The ETHOS definition and classification of homelessness and housing exclusion. European Journal of Homelessness, 6(2), 219-225.

Ellis, F., Munoz, S.-A., Narzisi, K., Bradley, S., \& Hall, J. (2020). Creating community and belonging in a designated housing estate for disabled people. Social Inclusion, 8(3), 66-76.

Fondation Abbé Pierre, \& FEANTSA. (2020). Fifth overview of housing exclusion in Europe 2020. Brussels: FEANTSA and Fondation Abbé Pierre.

Maloutas, T., Siatitsa, D., \& Balampanidis, D. (2020). Access to housing and social inclusion in a postcrisis era: Contextualizing recent trends in the city of Athens. Social Inclusion, 8(3), 5-15.

Matthews, P., \& Poyner, C. (2019). The experience of living in deprived neighbourhoods for LGBT+ people: Making home in difficult circumstances. Environment and Planning A: Economy and Space, 51(7), 1499-1515.

Matthews, P., Poyner, C., \& Kjellgren, R. (2019). Lesbian, gay, bisexual, transgender and queer experiences of homelessness and identity: Insecurity and home(o)normativity. International Journal of Housing Policy, 19(2), 232-253.

McCall, V., Ziegler, F., Robertson, J., Lovatt, M., Phillips, J., Porteus, J., ... Wallace, T. (2020). Housing and ageing: Let's get serious- "How do you plan for the future while addressing immediate chaos?" Social Inclusion, 8(3), 28-42.
McKee, K., Pearce, A., \& Leahy, S. (2020). The unequal impact of Covid-19 on Black, Asian, minority ethnic and refugee communities. UK Collaborative Centre for Housing Evidence. Retrieved from https://housingevidence.ac.uk/the-unequal-impactof-covid-19-on-black-asian-minority-ethnic-andrefugee-communities

O’Sullivan, S., O'Connell, C., \& Byrne, L. (2020). “Listen to what we have to say": Children and young people's perspectives on urban regeneration. Social Inclusion, 8(3), 77-87.

Robertson, J. M., Gibson, G., Pemble, C., Harrison, R., Strachan, K., \& Thorburn, S. (2020). "It is part of belonging": Walking groups to promote social health amongst people living with dementia. Social Inclusion, 8(3), 113-122.

Rolfe, S., \& Garnham, L. (2020). Neighbourhood impacts on wellbeing: The role of housing among low-income tenants. Social Inclusion, 8(3), 102-112.

Rolfe, S., Garnham, L., Godwin, J., Anderson, I., Seaman, P., \& Donaldson, C. (2020). Housing as a social determinant of health and wellbeing: Developing an empirically informed realist theoretical framework. BMC Public Health, 20. https://doi.org/10.1186/s12889020-09224-0

Sahlin, I. (2020). Who's homeless and whose homeless? Social Inclusion, 8(3), 43-53.

Simmel, G. (1965). The poor. Social Problems, 13(2), 118-140.

Tually, S., Skinner, W., Faulkner, D., \& Goodwin-Smith, I. (2020). (Re)Building home and community in the social housing sector: Lessons from a South Australian approach. Social Inclusion, 8(3), 88-101.

Tunstall, R. (2020). Is housing growth ever inclusive growth? Evidence from three decades of housing development in England and Wales, 1981-2011. Social Inclusion, 8(3), 16-27.

UN HABITAT. (2015). Housing at the centre of the new urban agenda. Nairobi: UN HABITAT.

United Nations. (2015). Transforming our world: The 2030 agenda for sustainable development. Geneva: United Nations.

United Nations Human Rights, Office of the High Commissioner. (2020). Call for input: COVID-19 and the right to housing. Ohchr.org. Retrieved from https://www.ohchr.org/EN/Issues/Housing/Pages/ callCovid19.aspx

\section{About the Authors}

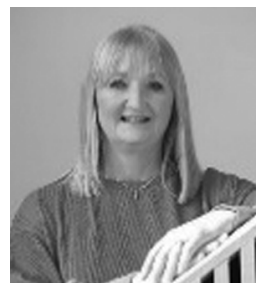

Isobel Anderson co-leads the Home, Housing and Community Research Programme at the University of Stirling. She has held more than 40 research awards and published widely for scholarly and practice audiences. Within the European Network for Housing Research (ENHR) Isobel has jointly co-ordinated two working groups: Welfare Policy, Homelessness and Social Exclusion (WELPHASE), 2004-2013, and Housing in Developing Countries, 2015-to date. She is on the international advisory committee of the European Journal of Homelessness. 

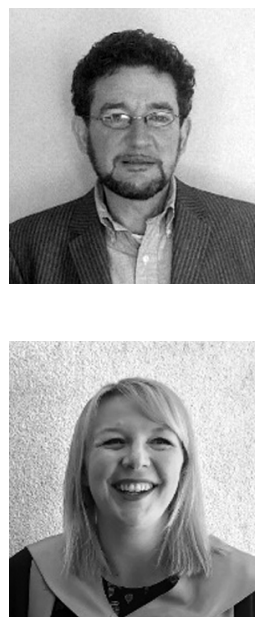

Joe Finnerty is Course Director of the Higher Diploma in Social Policy in the School of Applied Social Studies, University College Cork. His research interests are in the areas of tenure trends, housing precarity and homelessness. He is a coordinator of the Welfare Policy, Homelessness and Social Exclusion working group of the European Network of Housing Research and is a member of the Homeless Sub-Group of the Children and Young People's Services Committee Cork (CYPSYC).

Vikki McCall (PhD) explores housing and ageing in her work, focusing on the role of front-line workers, service users, volunteers and the policy process. She was part of the team that won the Sociological Review Prize for Outstanding Scholarship (2017) for work on tackling urban stigmatisation. Dr McCall is a Chartered member of the $\mathrm{CIH}$, Board Director for the Scottish Federation of Housing Associations and Board and Committee member for Parkhead Housing Association, Social Policy Association Executive and Social Policy \& Society. 